\title{
Assessment method for the impact of truck parking policy in urban areas
}

\author{
Li Lin ${ }^{1, a}$, Shanshan Chen ${ }^{2, b}$ and Zhuang $\mathrm{Hu}^{3, \mathrm{c}}$ \\ ${ }^{1}$ Automobile and Traffic Engineering College, Nanjing Forestry University, Nanjing, China \\ Corresponding author. Tel.: +86 13705180025 \\ ${ }^{2}$ Automobile and Traffic Engineering College, Nanjing Forestry University, Nanjing, China \\ Corresponding author. Tel.: +86 15205180295 \\ ${ }^{3}$ Automobile and Traffic Engineering College, Nanjing Forestry University, Nanjing, China \\ Corresponding author. Tel.: +86 18020105226 \\ aemail:743695641@qq.com, bemail:1203959439@qq.com, cemail:11490527@qq.com
}

\begin{abstract}
Keywords: Urban areas Freight parking Parking policy Traffic simulation
Abstract. In recent years, with the rapid development of urban industry and commerce, the number of freight cars is increasing, urban freight transportation has become an important part of urban transportation system. Urban truck parking policy includes time limit, pricing policy, management and enforcement of parking spaces. In this paper, a new method is developed to evaluate the impact of freight car parking policy. A parking choice simulation model is developed, and the feasibility of the model is verified by the example of Xinjiekou area in Nanjing city. It is concluded that the freight parking spaces on the road are advantageous to reduce the time of freight car parking to find a parking place, but it is not conducive to the parking of passenger cars. After all, the roadside parking space is limited in short supply.
\end{abstract}

\section{Introduction}

The central business district(CBD) of the city is the main destination for the logistics enterprises to carry out the distribution. The "last mile" of the central business district is the most expensive part of the logistics company to carry out the city's distribution costs. In the "last mile", truck drivers have to search for suitable parking spots on crowded city streets to facilitate loading and unloading. When can not find a suitable parking space, truck drivers will generally choose the nearest parking illegally, so "parking fines" become logistics and distribution of explicit costs, and this part of the cost with the passage of time is still in constant increase.

Truck parked on the city center business district problem is very important, and the situation is more and more serious. For example, in the central business district in Nanjing, there are a lot of trucks entering and loading cargo every day. Because of the planning construction and architectural design, the lack of the current logistics distribution vehicle parking supply, no place to stop is the city distribution vehicles often encountered embarrassment.

Freight parking problems in other countries are also very common in the city. Involved in domestic freight parking facilities of facilities planning study, few foreign in parking planning carried out earlier and and passenger traffic and freight traffic is considered separately, for freight car park and the central business district of loading and unloading of parking demand and location are discussed. Some management agencies have made some research on the problem of moving objects. These studies are intended to ease urban traffic congestion and improve the operational efficiency of commercial vehicles.

Urban parking policy needs data and judgment indicators, and so to determine the impact of policy, such as the time limit and pricing policies, etc.. At present, traffic simulation tools are more and more popular with urban traffic analysis. However, it is not entirely representative of the parking area. 
Although there is a bus stop simulation model and the choice of measurement model, but not for freight.

This paper mainly studies the vehicle parking policy, the development of new evaluation of the impact of parking policy tools.

\section{Domestic and international research status}

Truck parking policy.In the city center business district, construction intensive, the customer's demand is so high that the scarcity of roadside parking spaces, resulting in traffic congestion. In order to solve the problem of freight cars entering the city, the local standards have been established. The logistics and distribution system of the city center area is gradually realizing the standardization. The place to unload the goods in urban areas in Beijing has made clear rules and carried on the strict limit to the time of unloading cargo. Once in excess of the prescribed time, it will be punished accordingly. Some experts believe that we can use metered guide part of the driver to the outside road parking parking facilities, so you can avoid looking for parking spaces in the road leading to congestion[1]. Bus parking policy produces more roadside parking space which provides more opportunities for railway truck parking.

In many cities, freight parking policy would limit the time of the loading area to implement the separation of passenger parking and freight parking[2]. In Manhattan,New York City department of transportation assign the parking areas for trucks in the morning, later will provide for passenger parking areas. Most of the delivery of the goods will be completed before 12 o'clock at noon and have exclusive parking rights for trucks.

At present, the truck parking violations illegal phenomenon is very outstanding. It's imperative to strengthen parking enforcement. Through the mobile car video equipment, we quickly and efficiently complete the illegal evidence and so on. In recent years, Shanghai, Beijing, Shenzhen, Guangzhou and other large cities have also developed the relevant urban parking policy to solve the problem of parking and ease its impact on urban traffic congestion.

Parking simulation. Common parking simulation model is used to analyze the internal relations between the different parking behavior. The model ignored the dynamic effects of parking behavior and also did not take into account other parking characteristics including walking time and parking place supply and demand situation. Parking balance model proposed by Ommeren highlights the performance of the parking behavior features in the back and forth to find the time to drive a parking space.

Waraich and Axhausen further improved the MATSim model which was used to capture the effects of different parking behaviors. The model shows that different parking prices will cause drivers to make different parking options. But the model is not without shortcomings. It is not completely dynamic, leading to the driver to provide travel information directly, without taking into account the possibility of driving along the road to find parking spaces.

Kunnan Yi and zhichun Li studied stochastic dynamic traveler parking behavior in the traffic network, using the relation of supply and demand interaction, established the fixed point type parking behavior model, and designed a Monte Carlo simulation algorithm to solve the model[3].

Huan Ding etc. considered the effect of the time value and established a behavior model of curb parking cruise. This model takes the parking choice based on the time and quantifies the effect of parking price right inside the cruise. The model is helpful to analyze the key decision variables that affect the cruise parking behavior. The relationship between the variables is used to realize the optimization of the parking price.

Parking choice model.In 1991, Axhausen and Polak summarized parking behavior researches until the 1990s. They established a parking choice model on the basis of traveler parking intention survey data, which is used to analyze the driving travelers' choice of parking spaces and parking facilities[4]. In the same year, Young et al. summarized modeling method which is used to study the parking choice 
behavior in the parking model review analysis as distribution model, utility model, distribution model and optimization model. They analyzed the characteristics and applicability of various models.

In 2004, P.Bonsall and I.Palmer studied parking choice model using parking choice simulator of. The results showed that in addition to parking fees, travel distance, walking time outside, parking experience and information are also the important factors that affect when choice the parking.

In 2006, Southeast University Jun Chen and Zhiyong Zhou with the goal of convenient parking and minimum cost established a user before a trip to choose optimization model of parking facilities in order to improve the effectiveness of parking guidance. And the application of heuristic algorithm was used to solve the model.

Literature review.At present, there are a lot of research on passenger parking in urban areas. But there are few research on truck parking. In fact, truck parking search is also very important. Because, first of all, in the overall transport network, the number of trucks account for 5\% to $15 \%$ of all vehicles. Secondly, the frequency of truck parking is higher than the passenger parking. Passenger vehicles usually stop after a travel, and freight needs to stop at every station. Existing studies have neglected the parking of urban trucks which is also a big parking problem. The truck parking is different from the passenger vehicle stop. Freight needs delivery time. Some truck drivers will not be willing to spend a lot of time to find a parking space. Then they will be illegal to park vehicles. Therefore, it is not feasible to apply the passenger vehicle parking model directly to the truck. This paper is in order to eliminate the difference between the passenger vehicle parking model and the truck parking model. It mainly studies the parking problem and its impact on the road network[5].

\section{Data and methods}

The data included in this paper are the investigation of the truck drivers, the number of vehicles in the parking lot and the parking facilities within the scope of the survey. The parking facilities include on-street parking and off-street parking. In July 2015, in order to determine the truck parking demand, we carried out the collection of data. In the survey, we use freight parking number to estimate the number of parking demand. On Monday to Friday's 9:00 16:00, investigators interviewed the truck drivers in the parking lot to get the information, including the departure time, arrival time, parking location, walking distance and other information. The specific interview questions about parking is showed in Appendix A. A total of 180 investigators interviewed a truck driver, recorded about 1500 parking trips. This survey takes a random way, does not have a targeted, reflects the comprehensive survey in the area of the truck parking.

The study area is the Xinjiekou in Nanjing. This area is covered with all kinds of shopping malls, hotels, office buildings. This area contains Zhongshan East Road, Zhongshan South Road, Zhujiang Road and Hongwu Road.

Parking choice model. We choose logit model to determine the probability of parking in a location and find a more satisfactory parking point. The model can be written as :

$$
P_{i}=\frac{e^{\beta \chi_{i}}}{1+e^{\beta \chi_{i}}}
$$

$\beta$ is an estimated parameter vector, $i$ is the characteristic vector of the current parking position. The data of the model are obtained from the interview with the driver. The parking position can be obtained simultaneously.

For data collection, we should not only record the final stop point but also record the parking spots not selected. In the process of the driver's driving, we can get the parking address and the parking of the former station location. We can make use of Baidu maps to guess the possible driving routes from the parking front to the final parking location, and then provide the driver with two or three feasible parking points. However, there is a drawback is not able to access the relevant information in real time 
no parking spots. We can also get the walking distance to the destination, the number of car parking spaces, parking fees and other features of the price.

However, there are many uncertain factors that may affect the accuracy of the model in the course of the investigation. It stands to reason that the driver will choose the shortest path. But some drivers may not choose provided solutions and probably passing several parking spots to park the car. Alternatively, it may be no coincidence that the provided optimal stopping point may be full of parked vehicles, can not receive new vehicles entering the parking lot. In order to avoid these problems, investigators need to spend more experience and get more valuable information to ensure the accuracy of the model.

In order to clarify the influence of the change of the distance between the destination and the parking place on the choice of the parking place. The paper selects a logit model. The model uses moment estimation to estimate parameters. Specific parameters are shown in Table 1.

Table 1 Parameters of model for vehicle parking location

\begin{tabular}{ccc}
\hline Variable & Coefficient & t-Stat \\
Distance to destination & $-6.03 \mathrm{E}-02$ & -2.98 \\
On-street parking facility & -1.59 & -4.16 \\
Loading area parking facility & 2.23 & 2.10 \\
Constant & 2.23 & 5.98 \\
Log probably & -83.33 & \\
Pseudo R-squared & 0.2986 & \\
\hline
\end{tabular}

Through calculation, the model results is the square of the pseudo value is 0.2986 . And the distance coefficient of the destination is negative, which shows that the distance between the parking spot and the the location of final delivery is too far away. Truck drivers are unlikely to choose the parking point. The coefficient of curb parking facilities is negative. The truck drivers do not tend to put the car parked on the roadside parking. While the loading area of the parking facilities coefficient is positive, the truck driver is more likely to stop at the designated loading area.

Parking simulation model.In this paper, a peak hour parking simulation model is developed in the study area which is based on the actual data. During the peak period, Xinjiekou is facing a large-scale public travel activities. It is not only have a lot of employees in this period but also many consumers. If truck delivery the goods in the peak, it may face with the situation of road congestion. And in this time the supply of parking spaces is certainly inadequate. It will greatly increase the cost of travel.

In order to obtain the parking demand of freight vehicles and passenger vehicles, we conducted a survey of the residents of Nanjing city and vehicle parking survey. According to the survey results, the trip generation and trip attraction of passenger vehicles and trucks are calculated. In the study area of the road entrance and exit investigators take a cross counting method to get the number of vehicles entering the study area.

Every time when the vehicle reaches a parking facilities 300 meters away from the delivery points, we began to start the parking choice model. Through calculation and judgment, drivers choose to park in the facilities or continue searching for a better parking place. When a vehicle stops at a parking facility, it is also different to calculate the residence time of the vehicle. But we can find the inherent law between them according to the specific function.

The simulation model can be applied to both passenger vehicles and trucks. At a certain moment, the simulation model is started. The vehicle is tracked in the range of 300 meters away from the final destination. When the vehicle enters or leaves the parking spot, the free parking space of the parking lot is updated synchronously. Finally, the vehicle leaves the parking facility. The model stops.

In this simulation model, we calculate the four evaluation indicators, including the average search time of the vehicle, the average walking distance, the average access time and the total travel time of the vehicle. When the the value of these indicators is lower, the efficiency of parking will be the higher. 


\section{Scenario comparison}

This paper studies the parking choice simulation model in order to evaluate the impact of various parking policies. In order to test the availability of the model, we assume that the following three parking policies are proposed:

Scenario 1:

In the study area of all roads can be parked trucks and passenger vehicles. There is no limit.

Scenario 2:

Freight vehicles are prohibit to park in Zhongshan Road and Zhongshan South Road.

Scenario 3:

The parking facilities in Zhujianglu Road and Hongwu Road are only given to trucks. Although the freight vehicles are allowed to travel, but can not be parked, have to stop at the other places in the study area.

In order to make the model more persuasive, each scheme is implemented about 40 times. The average value and standard deviation of each index are calculated. The values of various indicators of freight vehicles and passenger vehicles are shown in Table 2.

Table2 Comparison of evaluation indexes of 3 kinds of scenarios

\begin{tabular}{|c|c|c|c|c|c|c|c|c|c|c|c|}
\hline & \multicolumn{4}{|c|}{ Search time(min) } & \multicolumn{4}{|c|}{ Walking distance(m) } & \multicolumn{2}{|c|}{ Access time $(\mathrm{min})$} & \multirow{3}{*}{$\begin{array}{c}\text { Mean of } \\
\text { total } \\
\text { travel } \\
\text { time } \\
\text { (min) }\end{array}$} \\
\hline & \multicolumn{2}{|c|}{$\begin{array}{l}\text { Freight } \\
\text { vehicles }\end{array}$} & \multicolumn{2}{|c|}{$\begin{array}{l}\text { Passenger } \\
\text { vehicles }\end{array}$} & \multicolumn{2}{|c|}{$\begin{array}{l}\text { Freight } \\
\text { vehicles }\end{array}$} & \multicolumn{2}{|c|}{$\begin{array}{c}\text { Passenger } \\
\text { vehicles }\end{array}$} & \multirow{2}{*}{$\begin{array}{c}\begin{array}{c}\text { Passenger } \\
\text { vehicle }\end{array} \\
\text { Mean }\end{array}$} & \multirow{2}{*}{$\begin{array}{c}\begin{array}{c}\text { Passenger } \\
\text { vehicles }\end{array} \\
\text { Mean }\end{array}$} & \\
\hline & Mean & SD & Mean & SD & Mean & $\mathrm{SD}$ & Mean & $\mathrm{SD}$ & & & \\
\hline Scenario 1 & 2.40 & 1.28 & 1.44 & 1.30 & 72.5 & 43.6 & 84.7 & 22.2 & 3.16 & 2.52 & 3533 \\
\hline Scenario 2 & 1.21 & 1.25 & 1.63 & 1.41 & 87.6 & 36.2 & 85.2 & 19.7 & 2.19 & 2.64 & 3497 \\
\hline Scenario 3 & 0.89 & 0.97 & 1.75 & 1.42 & 37.4 & 33.1 & 91.3 & 24.5 & 1.34 & 2.85 & 3439 \\
\hline
\end{tabular}

These three scenarios are compared with the four evaluation indexes of passenger vehicles and freight vehicles. Compared with the scenario 2, the scenario 1 sets up a special channel for the truck. The average value and variance of the search time are lower than that of the passenger vehicles. The search time of the goods in the scenario 3 is obviously reduced. This is due to the truck driver in the parking space when the vehicle is parked, drivers do not continue to spend time looking for other suitable parking points.

As can be seen from the Table 2, the truck walking distance in the scenario 2 is far than that in the scenario 1 and 3. This is because that vehicles are required to stop on the specified roadside parking spaces in scenario 2. They can not park nearby the place of the final delivery of goods. So, inevitably, they need to walk a long distance. Scenario 3 is different from the scenario 2. Vehicles can be parked near for the delivery of goods in the scenario 3.

On passenger vehicles, from the Table 2 we can see that the average search time for parking spaces have increased in the scenario 2 and scenario 3. Because of the specific parking space for freight vehicles, it's more difficult to find parking places for passenger vehicles. While the average pedestrian distance of the driver also increased accordingly. By comparison, we can directly see the differences between the various indicators of passenger vehicles and trucks.

Vehicle running back and forth to find a parking space virtually increases the travel time of the vehicle. And it also increases the amount of traffic on the road, affects the capacity of the road section, and increase the pressure on the road. The average value of the total road network travel time in the scenario 2 and scenario 1 is significantly lower than that in the scenario 3. 


\section{Conclusions and Outlook}

In order to evaluate the influence of parking policy, this paper presents a new simulation model of parking choice. The model can obtain the basic characteristic parameters of parking, including average walking distance, average parking search time, and so on. When planning parking facilities or providing parking policy, you can use the model to conduct simulation and investigate its feasibility. The model is more suitable for dense urban center area. The model can reasonably plan inside road parking space and improve the utilization rate and turnover of parking spaces.

This article make the Xinjiekou business center in Nanjing as a research area. The availability of the model is verified. Two scenarios which are different from the traditional policy of allowing trucks and buses to stop are proposed. They are aimed at the roadside parking of goods vehicles. Based on the new scheme, the time of searching for a parking space is reduced. At the same time, the time and the distance of the passenger vehicles search are increased. According to the comparison of the evaluation indexes, the influence of the road side parking spaces in the model can be easily seen.

In this paper, the influence of freight vehicles parking policy is studied. And the influence of other parking policies can be further studied. Parking policy has a lot of content, including the charging policy, time constraints, parking facilities management, etc.. Further research needs to be supported by more data.

\section{Appendix A. Parking survey questionnaire}

1-What type of car do you drive?

2- What are the things you transport?

3- Are you familiar with the nearby parking spaces?

4- Where is your destination? Where will you park your car?

5- Are you looking for a legal parking lot easier?

6- How long do you usually look for a parking lot?

7- How many stops will you call a day to deliver the goods?

8- Will you comply with all kinds of traffic signs?

9- What time of day is easier to park? Which period of time parking is more difficult?

$10-$ What is the reason that you will make illegal parking?

11- How many illegal parking tickets will you receive on average every day?

12- Do you think these tickets are reasonable?

13- What do you think is the most difficult to stop?

\section{References}

[1] Shoup, D.C.. Cruising for parking.Transp. Policy: Spec. Iss. Park. 13(6),479-486(2006).

[2] Bernbard O. Herzog. Federal Ministry for Economic Cooperation and Development(2011).

[3] Kunnan Yi, Zhichun Li, Journal of Changsha University of Science and Technology(Natural Science)(2006).

[4] Axhausen, K.W., Polak, J., 1991.Choice of Parking:stated preference approach.Transportation $18,59-81$.

[5] Zalewski, A.J, Buckley, S.M.,Weinber, R.. Regulating curb space: developing a framework to understand and improve curbside management. In: proceedings of the 91st Annual Meeting of the Transportation Research Board,Washington, DC, January(2011). 